\title{
The mediator role of the fear of COVID-19 in the relationship between psychological resilience and life satisfaction
}

\author{
Selim Gundogan ${ }^{1}$ (D) \\ Accepted: 19 February 2021 / Published online: 8 March 2021 \\ (C) The Author(s), under exclusive licence to Springer Science+Business Media, LLC part of Springer Nature 2021
}

\begin{abstract}
COVID-19, which has recently affected the world, has caused serious adversities in many areas as well as on the mental health of individuals. People have had a serious fearful mood due to situations such as catching COVID-19, having health problems after catching the disease, and worrying about infecting someone else. This negative mood is discussed in the literature through the concept of the fear of COVID-19. Accordingly, the mediator role of the fear of COVID-19 in the relationship between psychological resilience and life satisfaction was examined in this study. This study was conducted with 430 Turkish university students, 279 women and 151 men, who are between the ages of 18 and 30. The data of the study were collected with the psychological resilience, the fear of COVID-19 and life satisfaction scales. As a result of the analysis, it was concluded that psychological resilience is a negative predictor of the fear of COVID-19 and a positive predictor of life satisfaction, and that the fear of COVID19 is a negative predictor of life satisfaction. It was also concluded that the fear of COVID-19 mediates the relationship between psychological resilience and life satisfaction. The results are discussed in relation to the relevant literature, and suggestions are made for practitioners and researchers.
\end{abstract}

Keywords COVID-19 $\cdot$ Psychological resilience $\cdot$ The fear of COVID-19 $\cdot$ Life satisfaction

\section{Introduction}

As of December 2019, the whole world has faced coronavirus disease (COVID-19), a new type of disease that emerged in Wuhan, China (WHO, 2020a; Huang et al., 2020; Hui et al., 2020). After the first cases were seen in China, COVID-19 spread all over the world in a short time, cases were seen in 187 countries; it infected millions of people and caused hundreds of thousands of people to die (Covidvisualizer, 2020). Considering the serious spread of this disease and its causing the deaths of many people, it was declared as a "pandemic" by WHO on 11 March 2020 (WHO, 2020b). The first COVID-19 case in Turkey was seen on March 11, 2020 and then it infected a large number of people and caused the death of many people (Ministry of Health Turkey, 2020). COVID-19 spreads rapidly among people and is very easily transmitted from person to person (Sajadi et al., 2020). Therefore it has become necessary to take serious measures against COVID-19 and

Selim Gundogan

selimgundogan@ohu.edu.tr

1 Department of Educational Sciences, Niğde Ömer Halisdemir University, Niğde, Turkey serious restrictions have been imposed on many issues both in the whole world and Turkey [e.g. people's not going out and staying at home, not having close contact with each other and not coming together, interruption of education, travel restrictions between cities and countries] (Watkins, 2020).

Cases such as the emergence of COVID-19 in many countries of the world, its rapid spread and the death of some infected people have caused serious anxiety, fear and panic in people (Taylor et al., 2020; Zhi, 2020). Therefore, COVID19 has caused serious psychological problems in people of all age groups (Mo et al., 2020; Zhang, Wang, Rauch, \& Wei, 2020; Haktanir, Seki, \& Dilmaç, 2020; Feng et al., 2020; Evren, Evren, Dalbudak, Topcu, \& Kutlu, 2020; Yue, Zang, Le, \& An, 2020; Robles-Bello, Sánchez-Teruel, \& Naranjo, 2020). People's anxious and fearful mood resulting from their fear of being infected with COVID-19 is defined with the concept of "the fear of COVID-19" (Ahorsu et al., 2020). Studies have shown that the fear of COVID-19 causes many mental, cognitive and behavioural problems in individuals (Fitzpatrick, Harris, \& Drawve, 2020; Paolini, Maricchiolo, Pacilli, \& Pagliaro, 2020). Studies have concluded that the fear of COVID-19 causes depression, stress and anxiety (Lai et al., 2020; Bakioğlu, Korkmaz, \& Ercan, 2020; Satici, Gocet-Tekin, Deniz, \& Satici, 2020a; Wang et al., 2020). 
Accordingly, it can be argued that the fear of COVID-19 causes serious psychological problems in addition to health problems. Furthermore, studies have concluded that the fear of COVID-19 also has a negative effect on the life satisfaction of individuals (Satici et al., 2020a; Blasco-Belled, TejadaGallardo, Torrelles-Nadal, \& Alsinet, 2020). In addition, it has been suggested that psychological resilience has a negative effect on the fear of COVID-19, that is, individuals with high psychological resilience are less affected by the fear of COVID-19 (Mosheva et al., 2020; Y1ldırım \& Arslan, 2020a; Lee \& You, 2020). In this context, the relationships between the fear of COVID-19 and psychological resilience and life satisfaction are investigated in this study.

\section{Theoretical Background and Hypotheses}

\section{Psychological Resilience}

The concept of psychological resilience is defined as the ability of the individual to remain strong in the face of a negative situation and to resists against that negative situation (Rutter, 1999). According to Garmezy (1993), psychological resilience can be expressed as the ability of the individual to use his / her recovery power and return to his / her individual characteristics that existed before the stressful event he/she is experiencing. Studies have concluded that psychological resilience has a negative effect on depression, anxiety and stress (Hjemdal, Vogel, Solem, Hagen, \& Stiles, 2011; Mujeeb \& Zubair, 2012; Min et al., 2013; Hu, Xiao, Peng, Kuang, \& He, 2018). In these studies, it has been concluded that psychological resilience has a protective role against the negative psychological conditions experienced by individuals and increases the endurance of the individual. In addition, it has been suggested that psychological resilience plays a protective role against the fear of COVID-19, which occurs in individuals as a spiritual consequence of COVID-19, and individuals with high psychological resilience experience this fear less (Albott et al., 2020). As a matter of fact, it has been concluded that individuals with high psychological resilience experience less stress, depression and anxiety associated with COVID-19 (Barzilay et al., 2020). It was also found that psychological resilience is a negative predictor of COVID-19 burnout (Y1ldirım \& Solmaz, 2020) and COVID-19 anxiety (Labrague \& De los Santos, 2020). In this context, it is thought that psychological resilience has an important role in individuals' feeling the fear of COVID-19 less and being less affected by this fear. In addition, it has been suggested that individuals with good psychological resilience achieve better life satisfaction, and they are more peaceful and happier individuals than individuals with low psychological resilience (Gizir, 2007; Fletcher \& Sarkar, 2013). Studies that have found that psychological resilience is a positive predictor of life satisfaction also support this view (Bajaj \& Pande, 2016; Baş \& Yurdabakan, 2017; Prayag, Spector, Orchiston, \& Chowdhury, 2020; Y1ldırım \& Arslan, 2020b). As a result, psychological resilience has a negative effect on the fear of COVID-19 (Hypothesis-1), and a positive effect on life satisfaction (Hypothesis-2).

\section{Life Satisfaction}

Life satisfaction is defined as a concept that includes the individual's cognitive judgments about his/her personal life as a complement to happiness and subjective well-being (Diener, Emmons, Larsen, \& Griffin, 1985). In other words, life satisfaction constitutes the cognitive aspect of the subjective wellbeing concept, which is defined as the individual's cognitive and emotional evaluation of his/her life (Diener \& Diener, 2009). In fact, the concept of life satisfaction includes the individual's cognitive evaluations of his/her own life and has the feature of being a subjective judgment (Pavot \& Diener, 2008). In this context, it can be argued that individuals with high life satisfaction have more positive thoughts about themselves (Hawi \& Samaha, 2017). While negative situations such as fear, anxiety, stress that the individual has experienced decrease life satisfaction, many situations such as the individual's positive life experiences, social support, good friendship relations and being psychologically strong are factors that increase life satisfaction (Diener, 2009). It has been generally accepted that psychological resilience has a positive effect on life satisfaction (Liu, Wang, \& Lü, 2013) and that the fear of COVID-19, a condition seen in individuals recently, also negatively affects life satisfaction (Satici et al., 2020a; Rogowska, Kuśnierz, \& Bokszczanin, 2020). In other words, the fear of COVID-19 has a negative effect on life satisfaction (Hypothesis-3).

\section{The Present Study}

Recently, people around the world have experienced serious problems due to COVID-19 and have had to overcome many negative situations. While the COVID-19 pandemic has negative effects on people in many areas such as social, economic and health, psychological problems emerged as one of these negative effects. University students are one of the groups that COVID-19 negatively affects mental health (Chen, Sun, \& Feng, 2020). Both the interruption of university education for about a year and the serious change of daily life caused serious psychological problems for university students. Accordingly, university students were determined for the study as the sample. The fear of COVID-19, which is a psychological consequence of COVID-19, has been researched by many researchers, and the results of this state of fear and the factors reducing the effect of this state of fear have been the subject of investigation. In studies, the relationship between psychological resilience, which plays a protective role against the fear of COVID-19, and the 
stress, anxiety and burnout conditions caused by COVID-19 have been investigated (Y1ldirım \& Solmaz, 2020; Labrague $\&$ De los Santos, 2020). In addition, the relationship between life satisfaction, one of the concepts negatively affected by the fear of COVID-19, and COVID-19 has also been researched (Satici et al., 2020a; Rogowska et al., 2020). However, it is seen that that these three concepts have not been handled in a holistic manner. In this regard, it is thought that it is important to address the direct and indirect relationships between psychological resilience, the fear of COVID-19 and life satisfaction in this study in terms of contributing to the literature. Moreover, it is thought that the findings obtained in this study will guide psychologists, psychiatrists and psychological counsellors who provide mental health services to individuals with the fear of COVID-19 while conducting intervention and preventive mental health services, and will provide insights for studies to be carried out on this subject. In this context, the main purpose of this study is to examine the mediator role of the fear of COVID-19 in the relationship between psychological resilience and life satisfaction (Fig. 1). To this end, the following hypotheses were tested:

H1. Psychological resilience will be a negative predictor of the fear of COVID-19.

H2. Psychological resilience will be a positive predictor of life satisfaction.

H3. The fear of COVID-19 will be a negative predictor of life satisfaction.

H4. The fear of COVID-19 will have a mediator role in the relationship between psychological resilience and life satisfaction.

\section{Method}

\section{Participants}

COVID-19 has caused serious fear and anxiety in university students, and the fear of COVID-19 has led to negative consequences in university students (Chen et al., 2020; Sahu, 2020). Thus, the study group of this study is comprised of university students. Due to the risk of collecting face-to-face data arising from the pandemic, and as it was difficult to reach the participants, data were collected online. In this connection, the analyses were conducted on the data collected from a total of 430 Turkish university students aged $18-35$ ( mean $=22.30$, $\mathrm{SD}=3.75$ ) and participating on a volunteer basis. Of these 430 Turkish university students, 279 are females $(64.9 \%)$ and 151 are males $(35.1 \%)$.

\section{Measures}

\section{The Fear of COVID-19 Scale (FCS)}

The fear of COVID-19 scale was developed by Ahorsu et al. (2020) to measure the state of fear and anxiety caused by COVID-19 in people and it is a Likert type scale consisted of 7 items and a single factor. Each item on the scale is scored between 1 and 5 points. While the lowest score to be taken from the scale is 7 and the highest score is 35. Low scores taken from the scale indicate low fear of COVID-19, while higher scores indicate high fear of COVID-19. The scale was adapted to the Turkish culture by Satici et al. (2020a). The Cronbach's $\alpha$ value of the scale was found to be .87 . As a result of the confirmatory factor analysis (CFA), it was concluded that fit values indicated a good fit $(\mathrm{SRMR}=.061$; $\mathrm{GFI}=.936$; NFI $=.912$; IFI $=.915 ; \mathrm{CFI}=.915$; Satici et al., 2020a. In this study, the Cronbach's $\alpha$ value of the scale was found to be .84. Moreover, a confirmatory factor analysis was also conducted on the scale (Table 1).

\section{Short Psychological Resilience Scale (SPRS)}

The short psychological resilience scale was developed by Smith et al. (2008) to measure the psychological resilience of individuals and it is a Likert type scale consisted of 6 items and a single factor. Each item on the scale is scored between 1 and 5 points. While the lowest score to be taken from the scale is 6 and the highest score is 30 . Low scores indicate that individuals have low psychological resilience, while high scores indicate that the individual has high psychological resilience. The scale was adapted to the Turkish culture by Doğan (2015). The Cronbach's $\alpha$ value of the scale was found to be .83 . As a result of the confirmatory factor analysis (CFA), it was concluded that fit values indicated a good fit $(\mathrm{NFI}=0.99, \mathrm{NNFI}=0.99, \mathrm{CFI}=0.99, \mathrm{IFI}=0.99, \mathrm{RFI}=0.97$,

Fig. 1 Conceptual mediation model

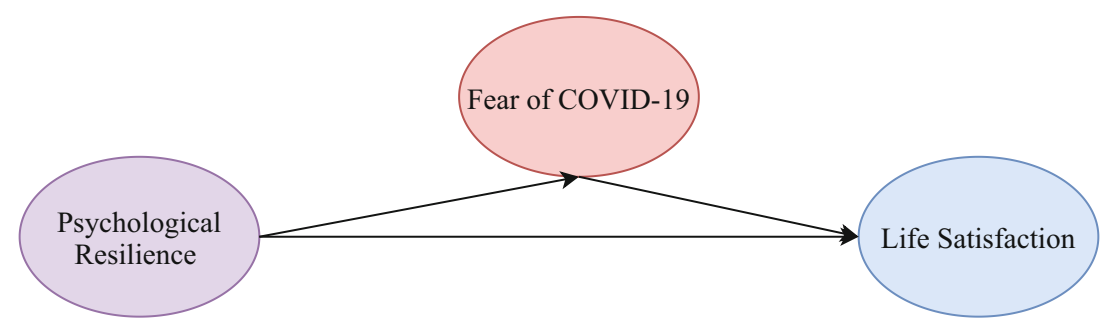


Table 1 CFA of the scales and the measurement model

\begin{tabular}{|c|c|c|c|c|c|c|}
\hline \multirow[t]{2}{*}{ Fit indices } & \multicolumn{3}{|c|}{ CFAs of scales } & \multirow[t]{2}{*}{ Measuring model } & \multirow[t]{2}{*}{ Structural model } & \multirow[t]{2}{*}{ Reference value(s) } \\
\hline & FCS & SPRS & LSS & & & \\
\hline$x^{2}$ & 18.55 & 9.33 & 6.89 & 376.54 & 352.26 & \\
\hline$p$ value & $<.001$ & $<.001$ & $<.001$ & $<.001$ & $<.001$ & \\
\hline df & 9 & 5 & 5 & 129 & 129 & \\
\hline$\chi^{2} / \mathrm{df}$ & 2.06 & 1.86 & 1.37 & 2.91 & 2.73 & $<3$ \\
\hline AGFI & .96 & .97 & .98 & .87 & .88 & $\geq .85$ \\
\hline GFI & .98 & .99 & .99 & .90 & .91 & $\geq .90$ \\
\hline TLI & .98 & .98 & .99 & .91 & .91 & $\geq .90$ \\
\hline CFI & .99 & .99 & .99 & .92 & .93 & $\geq .90$ \\
\hline IFI & .99 & .99 & .99 & .92 & .93 & $\geq .90$ \\
\hline RMSEA & .05 & .04 & .03 & .06 & .06 & $\leq .08$ \\
\hline SRMR & .02 & .02 & .01 & .05 & .05 & $\leq .05$ \\
\hline
\end{tabular}

$\mathrm{GFI}=0.99, \mathrm{AGFI}=0.96, \mathrm{RMSEA}=0.05, \mathrm{SRMR}=0.03$; Doğan, 2015). In this study, the Cronbach's $\alpha$ value of the scale was found to be .84 . Moreover, a confirmatory factor analysis was also conducted on the scale (Table 1).

\section{Life Satisfaction Scale (LSS)}

The life satisfaction scale was developed by Diener et al. (1985) to measure the degree of satisfaction taken by individuals from life and it is a measurement tool consisted of 5 items and a single factor. Each item on the scale is scored between 1 and 5 points. While the lowest score to be taken from the scale is 5 and the highest score is 25 . Low scores indicate that the life satisfaction of the individuals is low, while high scores indicate that the individual's life satisfaction is high. The scale was adapted to the Turkish culture by Dağlı and Baysal (2016). The Cronbach's $\alpha$ value of the scale was found to be .88 . As a result of the confirmatory factor analysis (CFA), it was concluded that fit values indicated a good fit (NFI = 0.99, NNFI = 1, CFI = 1, GFI = 0.99, AGFI =0.97, RMSEA = 0.03, SRMR = 0.01; Dağlı \& Baysal, 2016). In this study, the Cronbach's $\alpha$ value of the scale was found to be .85 . Moreover, a confirmatory factor analysis was also conducted on the scale (Table 1).

\section{Procedure}

First, the ethics committee was consulted for the ethical appropriateness of the study and the approval was obtained that it was ethically appropriate. In the next step, the study was conducted on university students. The collected data were transferred to the computer environment and then the analysis phase started.

\section{Data Analysis}

Before starting the analysis phase, the assumptions of outliers, normality, linearity, multicollinearity and singularity were examined (Pallant, 2013). After the required criteria were met, the data were analyzed. Moreover, it is suggested that the correlation value should be .90 maximum in order to avoid multicollinearity problem between binary variables (Pallant, 2013). In this context, it was concluded that the correlation value between binary variables is less than .90 . In addition, in order for the collected data to show a normal distribution, the skewness and kurtosis values should be between -1.5 and + 1.5 and in this study, the skewness and kurtosis values were found to be in this range, thus, the assumption of normality was satisfied in this study. For the structural equation modelling analysis, the fit values proposed to be acceptable in the literature $\left(\chi^{2} / \mathrm{d}<3\right.$; AGFI $\geq .85$; GFI, TLI, CFI and IFI $\geq .90$; REMSEA $\leq .08 ;$ SRMR $\leq .05)$ were taken as the criteria in this study (Tabachnick \& Fidell, 2013; Kline, 2015). In the structural equation modelling analysis, it has been suggested that the CFA on the scales should be conducted before testing the model (Bayram, 2010). In this regard, CFA was conducted on the scales and the measurement model was tested, then the formulated mediation model was tested.

\section{Results}

In this section, the results of the correlation and structural equation modelling analysis are presented. First, a correlation analysis was conducted to determine the binary correlations between the variables. As can be seen in Table 2, as a result of the correlation analysis, physiological resilience was found to be negatively correlated with the fear of COVID-19 $(\mathrm{r}=-.25 ; p<.01)$ and positively correlated with life satisfaction $(\mathrm{r}=.39 ; p<.01)$. A 
Table 2 Findings related to correlation analysis and descriptive statistics

\begin{tabular}{llllllll}
\hline & Mean & SD & Skewness & Kurtosis & 1 & 2 & 3 \\
\hline 1. Psychological Resilience & 18.86 & 4.63 & -.09 & .34 & 1 & & \\
2. Fear of COVID-19 & 17.81 & 5.22 & .26 & .10 & $-.25^{* *}$ & 1 & \\
3. Life Satisfaction & 14.65 & 3.88 & -.11 & -.02 & $.39^{* *}$ & $-.26^{* *}$ & 1 \\
${ }^{* *} p<.01$ & & & & & &
\end{tabular}

negative correlation was found between the fear of COVID-19 and life satisfaction $(\mathrm{r}=-.26 ; p<.01)$. Moreover, the correlation between the binary variables was found to be smaller than .90 and it was found that there is no multicollinearity problem (Pallant, 2013). The skewness and kurtosis values of the variables were found to be between -1.5 and +1.5 and thus it was concluded that the data showed a normal distribution (Tabachnick \& Fidell, 2013).

Before the model formulated was tested in the second stage of the findings, the CFA was conducted on the scales and the measurement model was tested. The results are presented in Table 1.

When Table 1 is examined, it is seen that the CFA of the scales and the fit values of the measurement model meet the desired criteria (Tabachnick \& Fidell, 2013; Kline, 2015). After reaching the conclusion that both the CFA of the scales and the fit values of the measurement model comply with the desired criteria, the phase of testing the hypotheses and mediation model was started. Results are presented in Table 3 and Fig. 2.

As can be seen in Table 3, psychological resilience is a negative and significant predictor of the fear of COVID-19 $(\beta=-.31 ; p<.001)$. Thus, the hypothesis 1 is supported. It was also found that psychological resilience is a positive and significant predictor of life satisfaction $(\beta=.38 ; p<.001)$. Thus, the hypothesis 2 is supported. The fear of COVID-19 was found to be a negative and significant predictor of life satisfaction $(\beta=-.16 ; p<.001)$. Thus, the hypothesis 3 is supported. Moreover, the fear of COVID-19 was found to have a mediator role in the relationship between psychological resilience and life satisfaction $(\beta=.05 ; p<.001)$. Thus, the hypothesis 4 is supported.

When Fig. 2 is examined, it is seen that psychological resilience explains $9 \%$ of the fear of COVID-19. Psychological resilience together with the fear of COVID-19 explain $21 \%$ of life satisfaction. The model fit indices were found to be as follows; $\chi^{2} / \mathrm{df}=2.73, \mathrm{AGFI}=.88, \mathrm{GFI}=.91, \mathrm{TLI}=.91$, $\mathrm{CFI}=.93, \mathrm{IFI}=.93, \mathrm{RMSEA}=.06$ and $\mathrm{SRMR}=.05$. These values show that the model in which the mediator role of the fear of COVID-19 in the relationship between psychological resilience and life satisfaction was tested was confirmed (Tabachnick \& Fidell, 2013; Kline, 2015). Thus, it can be argued that the fear of COVID-19 has a partial mediator role in the relationship between psychological resilience and life satisfaction $(\beta=.05 ; p<.001)$.

\section{Discussion}

Recently, COVID-19, which has seriously affected the world, has caused many health, economic and social problems as well as serious psychological problems. The concept of the fear of COVID-19 has been a topic investigated by researchers. In this study, the mediator role of the fear of COVID-19 in the relationship between psychological resilience and life satisfaction in university students was investigated.

The first hypothesis tested in this study was whether psychological resilience is a significant predictor of the fear of COVID-19. In this regard, it was found that psychological resilience is a negative predictor of the fear of COVID-19. Thus, this hypothesis was supported. This result shows that psychological resilience has a negative effect on the fear of COVID-19; that is, individuals having a high level of psychological resilience experience less fear of COVID-19 and are less affected by this negative condition. Findings reported in the literature also support the result of this study (Albott et al., 2020; Y1ldirım \& Solmaz, 2020; Barzilay et al., 2020; Labrague \& De los Santos, 2020; Mosheva et al., 2020;
Table 3 Test results of the hypotheses

\begin{tabular}{lcccc}
\hline Standardized direct and indirect ad total effects & $\beta$ & S.E. & LCL & UCL \\
\hline Standardized direct effects & & & & \\
H1. Psychological resilience $\rightarrow$ Fear of COVID-19 & -.31 & .055 & -.405 & -.185 \\
H2. Psychological RESILIENCE $\rightarrow$ life satisfaction & .38 & .057 & .279 & .502 \\
H3. Fear of COVID-19 $\rightarrow$ life satisfaction & -.16 & .057 & -.279 & -.058 \\
Standardized indirect effect & & & & \\
H4. Psychological resilience $\rightarrow$ Fear of COVID-19 $\rightarrow$ Life Satisfaction & .05 & .020 & .014 & .096 \\
\hline
\end{tabular}

SE Standard Error, LCL Lower Confidence Limit, UCL Upper Confidence Limit 


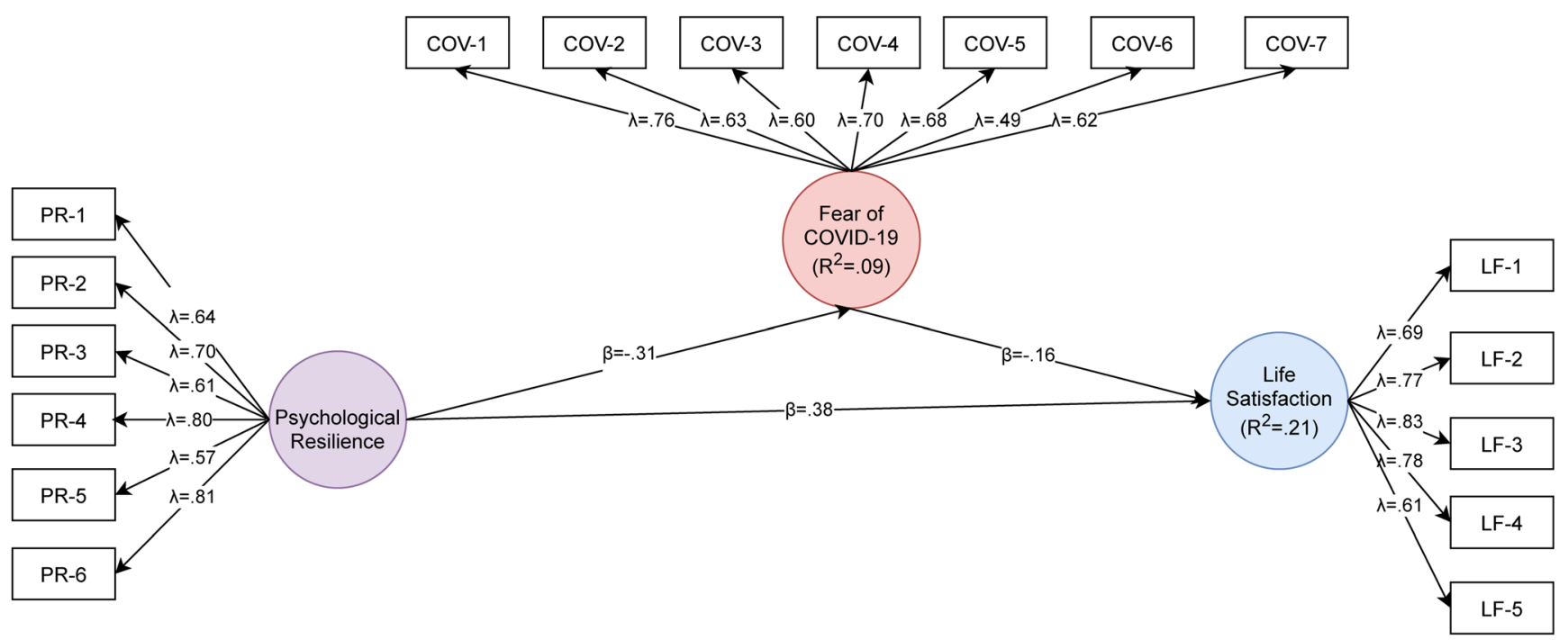

Fig. 2 The result of mediation model

Y1ldırım \& Arslan, 2020a; Lee \& You, 2020; Killgore, Taylor, Cloonan, \& Dailey, 2020).

The second hypothesis tested in this study was whether psychological resilience is a predictor of life satisfaction. In this regard, it was found that psychological resilience is a positive predictor of life satisfaction. As a result, the hypothesis was supported. Thus, it can be said that individuals having higher levels of psychological resilience have higher life satisfaction. The findings reported in the literature also support the result of this study (Bajaj \& Pande, 2016; Baş \& Yurdabakan, 2017; Prayag et al., 2020; Yıldırım \& Arslan, 2020b; Zheng, Huang, \& Fu, 2020; Miranda \& Cruz, 2020; Yang, Xia, \& Zhou, 2020).

The third hypothesis tested in this study was whether the fear of COVID-19 is a significant predictor of life satisfaction. In this regard, it was found that the fear of COVID-19 is a negative predictor of life satisfaction. As a result, this hypothesis was supported. Thus, it can be argued that the fear of COVID-19 has a negative effect on individuals' life satisfaction. This finding obtained in this study is supported by the results of other studies in the literature (Satici et al., 2020a; Rogowska et al., 2020; Blasco-Belled et al., 2020; Özmen, Özkan, Özer, \& Yanardăg, 2021; Gawrych, Cichoń, \& Kiejna, 2021).

The fourth and main hypothesis tested in this study was whether the fear of COVID-19 has a mediator role in the relationship between psychological resilience and life satisfaction. After the confirmation of the three hypotheses, this hypothesis was tested. It was concluded that the fear of COVID19 has a partial mediator role in the relationship between psychological resilience and life satisfaction. As a result, this hypothesis was also supported. Thus, it can be argued that as well as the direct effect of psychological resilience on life satisfaction, the fear of COVID-19 has an indirect effect on it. In other words, psychological resilience affects the fear of COVID-19 and the fear of COVID-19 affects life satisfaction. There is no study in the literature directly supporting the result of this study. However, in a similar study, Satici et al., 2020b) found that the fear of COVID-19 and rumination have a mediator role in the relationship between intolerance to uncertainty and mental well-being. In the study, it was found that intolerance to uncertainty increased the fear of COVID-19 and the fear of COVID-19 decreased mental well-being, which is a concept similar to life satisfaction (Satici et al., 2020b). This finding supports the result of this study.

\section{Limitations and Implications}

This study has some limitations. The first limitation is that the data were collected from university students. In further research, inclusion of participants from different age groups and different professions can minimize this limitation. Another limitation of this study is that the data were collected by means of self-report measurement tools. This limitation can be minimized by diversifying the measurement tools including qualitative data collection tools such as observations and interviews. Another limitation of the study is that the participants were not diagnosed with COVID-19. In future research, inclusion of the individuals diagnosed with COVID-19 can minimize this limitation. Moreover, this study is a cross-sectional study. Future research can be conducted longitudinally and experimentally.

In line with the results, some implications have been drawn out and some suggestions have been made. According to the results; it can be argued that psychological support activities should be increased and psychological counseling centers should be made more active in order to reduce the negative 
effects of COVID-19 fear in individuals after face-to-face training begins. In this context, the negative situations caused by the fear of COVID-19 can be overcome more quickly by conducting studies to increase the psychological resilience of university students. Besides studies on mental health at universities can focus on efforts to increase life satisfaction, which is negatively affected by the fear of COVID-19. Thus, the increasing of life satisfaction of university students can be expected. In addition, considering that the pandemic continues, it can be stated that it is important to provide psychological support for university students through online therapies and psychological counseling. Therefore, it is supposed that the online studies will reflect well on the life satisfaction of students and they will experience fewer negative psychological consequences caused by the fear of COVID-19.

\section{Conclusion}

In conclusion, it was found that psychological resilience has an effect on life satisfaction through the fear of COVID-19. Moreover, psychological resilience was found to have a negative effect on the fear of COVID19 while it has a positive effect on life satisfaction. The fear of COVID-19 was found to have a negative effect on life satisfaction. Thus, it can be argued that strengthening individuals' psychological resilience by means of therapies, psychological counselling, group psychological counselling and psycho-social intervention activities would have an important role in the elimination of negative psychological effects of fear, anxiety and stress caused by COVID-19. Given that individuals experiencing less fear of COVID-19 will have higher life satisfaction and take more pleasure from life, it can be argued that psychological intervention studies to be conducted will be important in terms of increasing life satisfaction in individuals.

Funding This research has not received specific support from public sector agencies, the commercial sector or non-profit organisations.

Data Availability The datasets generated during and/or analysed during the current study are available from the corresponding author on reasonable request.

\section{Declarations}

Ethical Approval All procedures performed in studies involving human participants were in accordance with the ethical standards of the institutional and/or national research committee and with the 1964 Helsinki declaration and its later amendments or comparable ethical standards.

Informed Consent Informed consent was obtained from all individual participants included in the study.
Conflict of Interest The authors declared no conflicts of interest with respect to the research, authorship, and/or publication of this article.

\section{References}

Ahorsu, D. K., Lin, C. Y., Imani, V., Saffari, M., Griffiths, M. D., \& Pakpour, A. H. (2020). The fear of COVID- 19 scale: Development and initial validation. International Journal of Mental Health and Addiction. https://doi.org/10.1007/s11469-02000270-8.

Albott, C. S., Wozniak, J. R., McGlinch, B. P., Wall, M. H., Gold, B. S., \& Vinogradov, S. (2020). Battle buddies: Rapid deployment of a psychological resilience intervention for health care workers during the coronavirus disease 2019 pandemic. Anesthesia and Analgesia., 131, 43-54. https://doi.org/10.1213/ANE.0000000000004912.

Bajaj, B., \& Pande, N. (2016). Mediating role of resilience in the impact of mindfulness on life satisfaction and affect as indices of subjective well-being. Personality and Individual Differences, 93, 63-67. https://doi.org/10.1016/j.paid.2015.09.005.

Bakioğlu, F., Korkmaz, O., \& Ercan, H. (2020). Fear of COVID-19 and positivity: Mediating role of intolerance of uncertainty, depression, anxiety, and stress. International Journal of Mental Health and Addiction, 1. https://doi.org/10.1007/s11469-020-00331-y.

Barzilay, R., Moore, T. M., Greenberg, D. M., DiDomenico, G. E., Brown, L. A., White, L. K., Gur, R. C., \& Gur, R. E. (2020). Resilience, COVID-19-related stress, anxiety and depression during the pandemic in a large population enriched for healthcare providers. Translational Psychiatry, 10(1), 1-8. https://doi.org/10.1038/ s41398-020-00982-4.

Baş, A. U., \& Yurdabakan, İ. (2017). Psikolojik sağlamlık ve okul ikliminin ortaokul öğrencilerinin yaşam doyumunu yordama gücü [the predictive value of resilience and school climate in life satisfaction among middle school students]. Mehmet Akif Ersoy Üniversitesi Eğitim Fakültesi Dergisi, 1(41), 202-214.

Bayram, N. (2010). Yapısal eşitlik modellemesine giriş, AMOS uygulamalarlintroduction to structural equation modeling, AMOS applications]. Bursa: Ezgi Pub.

Blasco-Belled, A., Tejada-Gallardo, C., Torrelles-Nadal, C., \& Alsinet, C. (2020). The costs of the COVID-19 on subjective well-being: An analysis of the outbreak in Spain. Sustainability, 12(15), 6243. https://doi.org/10.3390/su12156243.

Chen, B., Sun, J., \& Feng, Y. (2020). How have COVID-19 isolation policies affected young people's mental health?-evidence from Chinese college students. Frontiers in psychology, 11. https://doi. org/10.3389/fpsyg.2020.01529.

Covidvisualizer. (2020). Covid 19 visualizer. Retrieved 5 Sem 2020 from: https://www.covidvisualizer.com

Dağl1, A., \& Baysal, N. (2016). Yașam doyumu ölçeğinin Türkçe’ye uyarlanması: Geçerlik ve güvenirlik çalışması [adaptation of the satisfaction with life scale into Turkish: the study of validity and reliability]. Elektronik Sosyal Bilimler Dergisi, 15(59), 1250-1262. https://doi.org/10.17755/esosder.75955.

Diener, E. (2009). Assessing well-being: The collected works of Ed Diener (Vol. 331). New York, NY: Springer.

Diener, E., \& Diener, M. (2009). Cross-cultural correlates of life satisfaction and self-esteem, In Culture and well-being (pp. 71-91). Dordrecht: Springer.

Diener, E. D., Emmons, R. A., Larsen, R. J., \& Griffin, S. (1985). The satisfaction with life scale. Journal of Personality Assessment, 49(1), 71-75. https://doi.org/10.1207/s15327752jpa4901 13.

Doğan, T. (2015). Adaptation of the brief resilience scale into Turkish: A validity and reliability study. The Journal of Happiness \& WellBeing, 3(1), 93-102. 
Evren, C., Evren, B., Dalbudak, E., Topcu, M., \& Kutlu, N. (2020). Measuring anxiety related to COVID-19: A Turkish validation study of the coronavirus anxiety scale. Death Studies, 1-7. https://doi.org/ 10.1080/07481187.2020.1774969.

Feng, L. S., Dong, Z. J., Yan, R. Y., Wu, X. Q., Zhang, L., Ma, J., \& Zeng, Y. (2020). Psychological distress in the shadow of the COVID-19 pandemic: Preliminary development of an assessment scale. Psychiatry Research, 113202, 113202. https://doi.org/10. 1016/j.psychres.2020.113202.

Fitzpatrick, K. M., Harris, C., \& Drawve, G. (2020). Fear of COVID-19 and the mental health consequences in America. Psychological trauma: theory, research, practice, and policy., 12(S1), S17-S21. https://doi.org/10.1037/tra0000924.

Fletcher, D., \& Sarkar, M. (2013). Psychological resilience: A review and critique of definitions, concepts, and theory. European Psychologist, 18(1), 12-23. https://doi.org/10.1027/1016-9040/a000124.

Garmezy, N. (1993). Children in poverty: Resilience despite risk. Psychiatry, 56, 127-136. https://doi.org/10.1080/00332747.1993. 11024627.

Gawrych, M., Cichoń, E., \& Kiejna, A. (2021). COVID-19 pandemic fear, life satisfaction and mental health at the initial stage of the pandemic in the largest cities in Poland. Psychology, Health \& Medicine, 26(1), 107-113. https://doi.org/10.1080/13548506.2020. 1861314.

Gizir, C. (2007). Psikolojik sağlamlık, risk faktörleri ve koruyucu faktörler üzerine bir derleme çalışması [A literature review of studies on resilience, risk, and protective factors]. Türk Psikolojik Danışma ve Rehberlik Dergisi, 3(28), 113-128.

Haktanir, A., Seki, T., \& Dilmaç, B. (2020). Adaptation and evaluation of Turkish version of the fear of COVID-19 scale. Death Studies, 1-9. https://doi.org/10.1080/07481187.2020.1773026.

Hawi, N. S., \& Samaha, M. (2017). The relations among social media addiction, self-esteem, and life satisfaction in university students. Social Science Computer Review, 35(5), 576-586. https://doi.org/ 10.1177/0894439316660340.

Hjemdal, O., Vogel, P. A., Solem, S., Hagen, K., \& Stiles, T. C. (2011). The relationship between resilience and levels of anxiety, depression, and obsessive-compulsive symptoms in adolescents. Clinical Psychology \& Psychotherapy, 18(4), 314-321. https://doi.org/10. 1002/cpp.719.

Hu, T., Xiao, J., Peng, J., Kuang, X., \& He, B. (2018). Relationship between resilience, social support as well as anxiety/depression of lung cancer patients: A cross-sectional observation study. Journal of Cancer Research and Therapeutics, 14(1), 72-77. https://doi.org/ 10.4103/jcrt.JCRT_849_17.

Huang, C., Wang, Y., Li, X., Ren, L., Zhao, J., Hu, Y., ... \& Cheng, Z. (2020). Clinical features of patients infected with 2019 novel coronavirus in Wuhan, China. The lancet, 395(10223), 497-506. https:// doi.org/10.1016/S0140-6736(20)30183-5.

Hui, D. S., Azhar, E. I., Madani, T. A., Ntoumi, F., Kock, R., Dar, O., ... \& Petersen, E. (2020). The continuing 2019-nCoV epidemic threat of novel coronaviruses to global health-The latest 2019 novel coronavirus outbreak in Wuhan, China. International Journal of Infectious Diseases, 91, 264-266.

Killgore, W. D., Taylor, E. C., Cloonan, S. A., \& Dailey, N. S. (2020). Psychological resilience during the COVID-19 lockdown. Psychiatry Research, 291, 113216. https://doi.org/10.1016/j. psychres.2020.113216.

Kline, R. B. (2015). Principles and practice of structural equation modeling. Guilford Press.

Labrague, L. J., \& De los Santos, J. A. A. (2020). COVID-19 anxiety among front-line nurses: Predictive role of organisational support, personal resilience and social support. Journal of Nursing Management, 28(7), 1653-1661. https://doi.org/10.1111/jonm. 13121.
Lai, J., Ma, S., Wang, Y., Cai, Z., Hu, J., Wei, N., et al. (2020). Factors associated with mental health outcomes among health care workers exposed to coronavirus disease 2019. JAMA Network Open, 3(3), e203976. https://doi.org/10.1001/jamanetworkopen.2020.3976.

Lee, M., \& You, M. (2020). Psychological and behavioral responses in South Korea during the early stages of coronavirus disease 2019 (COVID-19). International Journal of Environmental Research and Public Health, 17(9), 2977. https://doi.org/10.3390/ ijerph17092977.

Liu, Y., Wang, Z., \& Lü, W. (2013). Resilience and affect balance as mediators between trait emotional intelligence and life satisfaction. Personality and Individual Differences, 54(7), 850-855. https://doi. org/10.1016/j.paid.2012.12.010.

Min, J. A., Jung, Y. E., Kim, D. J., Yim, H. W., Kim, J. J., Kim, T. S., Lee, C. U., Lee, C., \& Chae, J. H. (2013). Characteristics associated with low resilience in patients with depression and/or anxiety disorders. Quality of Life Research, 22(2), 231-241. https://doi.org/10. 1007/s11136-012-0153-3.

Ministry of Health Turkey. (2020). https://covid19bilgi.saglik.gov.tr/tr/.

Miranda, J. O., \& Cruz, R. N. C. (2020). Resilience mediates the relationship between optimism and well-being among Filipino university students. Current Psychology. https://doi.org/10.1007/s12144020-00806-0.

Mo, Y., Deng, L., Zhang, L., Lang, Q., Liao, C., Wang, N., Qin, M., \& Huang, H. (2020). Work stress among Chinese nurses to support Wuhan in fighting against COVID-19 epidemic. Journal of Nursing Management, 28, 1002-1009. https://doi.org/10.1111/jonm.13014.

Mosheva, M., Hertz-Palmor, N., Dorman Ilan, S., Matalon, N., Pessach, I. M., Afek, A., Ziv, A., Kreiss, Y., Gross, R., \& Gothelf, D. (2020). Anxiety, pandemic-related stress and resilience among physicians during the COVID-19 pandemic. Depression and Anxiety, 37(10), 965-971. https://doi.org/10.1002/da.23085.

Mujeeb, A., \& Zubair, A. (2012). Resilience, stress, anxiety and depression among internally displaced persons affected by armed conflict. Pakistan Journal of Social And Clinical Psychology, 10(2), 20-26.

Özmen, S., Özkan, O., Özer, Ö., \& Yanardağ, M. Z. (2021). Investigation of COVID-19 fear, well-being and life satisfaction in Turkish society. Social Work in Public Health, 1-14. https://doi.org/10.1080/ 19371918.2021.1877589.

Pallant, J. (2013). SPSS survival manual. McGraw-Hill Education (UK).

Paolini, D., Maricchiolo, F., Pacilli, M. G., \& Pagliaro, S. (2020). COVID-19 lockdown in Italy: The role of social identification and social and political trust on well-being and distress. Current Psychology. https://doi.org/10.1007/s12144-020-01141-0.

Pavot, W., \& Diener, E. (2008). The satisfaction with life scale and the emerging construct of life satisfaction. The Journal of Positive Psychology, 3(2), 137-152. https://doi.org/10.1080/17439760701756946.

Prayag, G., Spector, S., Orchiston, C., \& Chowdhury, M. (2020). Psychological resilience, organizational resilience and life satisfaction in tourism firms: Insights from the Canterbury earthquakes. Current Issues in Tourism, 23(10), 1216-1233. https://doi.org/10. 1080/13683500.2019.1607832.

Robles-Bello, M. A., Sánchez-Teruel, D., \& Naranjo, N. V. (2020). Variables protecting mental health in the Spanish population affected by the COVID-19 pandemic. Current Psychology. https://doi. org/10.1007/s12144-020-01132-1.

Rogowska, A. M., Kuśnierz, C., \& Bokszczanin, A. (2020). Examining anxiety, life satisfaction, general health, stress and coping styles during COVID-19 pandemic in polish sample of university students. Psychology Research and Behavior Management, 13, 797-811. https://doi.org/10.2147/PRBM.S266511.

Rutter, M. (1999). Resilience concepts and findings: Implications for family therapy. Journal of Family Therapy, 21, 119-144. https:// doi.org/10.1111/1467-6427.00108.

Sahu, P. (2020). Closure of universities due to coronavirus disease 2019 (COVID-19): Impact on education and mental health of students and 
academic staff. Cureus, 12(4), e7541. https://doi.org/10.7759/ cureus. 7541 .

Sajadi, M. M., Habibzadeh, P., Vintzileos, A., Shokouhi, S., MirallesWilhelm, F., \& Amoroso, A. (2020). Temperature and latitude analysis to predict potential spread and seasonality for COVID-19. Available at SSRN, 3550308.

Satici, B., Gocet-Tekin, E., Deniz, M. E., \& Satici, S. A. (2020a). Adaptation of the fear of COVID-19 scale: Its association with psychological distress and life satisfaction in Turkey. International Journal of Mental Health and Addiction. https://doi.org/10.1007/ s11469-020-00294-0.

Satici, B., Saricali, M., Satici, S. A., \& Griffiths, M. D. (2020b). Intolerance of uncertainty and mental wellbeing: Serial mediation by rumination and fear of COVID-19. International Journal of Mental Health and Addiction. https://doi.org/10.1007/s11469-02000305-0.

Smith, B. W., Dalen, J., Wiggins, K., Tooley, E., Christopher, P., \& Jennifer Bernard, J. (2008). The brief resilience scale: Assessing the ability to bounce back. International Journal of Behavioral Medicine, 15(3), 194-200. https://doi.org/10.1080/10705500802222972.

Tabachnick, B. G., \& Fidell, L. S. (2013). Using multivariate statistics. Pearson Education.

Taylor, S., Landry, C., Paluszek, M., Fergus, T. A., McKay, D., \& Asmundson, G. J. (2020). Development and initial validation of the COVID stress scales. Journal of Anxiety Disorders, 102232, 102232. https://doi.org/10.1016/j.janxdis.2020.102232.

Wang, C., Pan, R., Wan, X., Tan, Y., Xu, L., McIntyre, R. S., Choo, F. N., Tran, B., Ho, R., Sharma, V. K., \& Ho, C. (2020). A longitudinal study on the mental health of general population during the COVID19 epidemic in China. Brain, Behavior, and Immunity, 87, 40-48. https://doi.org/10.1016/j.bbi.2020.04.028.

Watkins, J. (2020). Preventing a covid-19 pandemic. BMJ, 368, m810. https://doi.org/10.1136/bmj.m810.

World Health Organization. (2020a). Novel coronavirus (2019-nCoV) Situation Report - 1. Retrieved 5 Sem 2020 from: https://www. who.int/docs/default-source/coronaviruse/situation-reports/ 20200121-sitrep-1-2019-ncov.pdf?sfvrsn=20a99c10 4.

World Health Organization. (2020b). Coronavirus disease 2019 (COVID-19) Situation Report - 51. Retrieved 5 Sem 2020 from: https://www.who.int/docs/default-source/coronaviruse/situationreports/20200311-sitrep-51-covid-19.pdf?sfvrsn=1ba62e57 10 .

Yang, C., Xia, M., \& Zhou, Y. (2020). How is perceived social support linked to life satisfaction for individuals with substance-use disorders? The mediating role of resilience and positive affect. Current Psychology. https://doi.org/10.1007/s12144-020-00783-4.

Ylldırım, M., \& Arslan, G. (2020a). Exploring the associations between resilience, dispositional hope, subjective well-being, and psychological health among adults during early stage of COVID-19. PsyArXiv, 1-27. https://doi.org/10.31234/osf.io/vpu5q.

Yıldırım, M., \& Arslan, G. (2020b). Exploring the associations between resilience, dispositional hope, subjective well-being, and psychological health among adults during early stage of COVID-19. Current Psychology. https://doi.org/10.1007/s12144-020-01177-2.

Yıldırım, M., \& Solmaz, F. (2020). COVID-19 burnout, COVID-19 stress and resilience: Initial psychometric properties of COVID-19 burnout scale. Death Studies., 1-9. https://doi.org/10.1080/ 07481187.2020.1818885.

Yue, J., Zang, X., Le, Y., \& An, Y. (2020). Anxiety, depression and PTSD among children and their parent during 2019 novel coronavirus disease (COVID-19) outbreak in China. Current Psychology. https://doi.org/10.1007/s12144-020-01191-4.

Zhang, S. X., Wang, Y., Rauch, A., \& Wei, F. (2020). Unprecedented disruption of lives and work: Health, distress and life satisfaction of working adults in China one month into the COVID-19 outbreak. Psychiatry Research, 112958. https://doi.org/10.1016/j.psychres. 2020.112958.

Zheng, W., Huang, Y., \& Fu, Y. (2020). Mediating effects of psychological resilience on life satisfaction among older adults: A crosssectional study in China. Health \& Social Care in the Community, 28(4), 1323-1332. https://doi.org/10.1111/hsc.12965.

Zhi, Z. L. (2020). The epidemiological characteristics of an outbreak of 2019 novel coronavirusdiseases (COVID-19) in China. US National Library of Medicine National Institutes of Health, 41(2), 145-151. https://doi.org/10.3760/cma.j..0254-6450.2020.02.003.

Publisher's Note Springer Nature remains neutral with regard to jurisdictional claims in published maps and institutional affiliations. 